\title{
PUBLIC ADMINISTRATION: ROBUSTNESS AND THE SYSTEMIC GENESIS ASPECT
}

\author{
Oleksandr Akimov ${ }^{1}$ \\ ${ }^{1}$ Ph.D. (Public Administration), Assistant Professor, Interregional Academy of Personnel \\ Management, Kiev, Ukraine, e-mail: 1970aaa@ukr.net; ORCID: https://orcid.org/0000-0002-9557- \\ 2276
}

Abstract. The article reveals the concept of robustness of the system of professional activity of civil servants as one of its properties. The essence of the robustness of the system of professional activity of civil servants in the conditions of system genesis is determined.

To clarify the specifics, nature and development of the system of professional activity of civil servants, its properties were analyzed, additional possibilities of functioning were revealed, and weak points were identified for developing ways and means of effective development. The essence of the phenomenon of robustness to the system of professional activity of civil servants in the context of forming the concept of system genesis of professional activity of civil servants is revealed. An important sign of the robustness of the system genesis of the professional activities of civil servants is the property of the system to produce what it needs. This explains the concept of systemogenesis of complex systems, to which we also refer the system of professional activity of public servants. That is, a system that can act both independently and controlled from the outside can have the ability, under certain conditions, to function independently and create corresponding products. In addition, signs of the robustness of the psychological system of activity of civil servants as one of the components of the system of professional activity of civil servants were revealed.

It is concluded that the concept of robustness in the context of the analysis of the professional activities of civil servants is applied to the system of professional activities of civil servants. It is defined in a broad sense that the robustness of the system of professional activity of civil servants is a property of the system to maintain effectiveness and stability margin when changing the parameters of its functioning. In particular, structural and nonstructural uncertainties are identified that determine the change in the quantity and quality of system elements. System genesis is a process of self-organization in the narrow sense, therefore, robsastern system genesis is the ability of the processes of self-organization of the system to preserve this property, its effectiveness if the self-organization of its individual elements or subsystems fails. That is, if the action of self-organization of one of the components of the system of professional activity of public servants fails, the system retains the ability to self-organize and maintain its effectiveness.

Keywords: professional competence, civil service, civil servant, professionalization of civil servants, development of civil service, professional activity, professional activities of civil servants, systemogenesis, robustness.

JEL Classification: D30, D73, D78

Formulas: 0; fig.: 0; tabl.: 0; bibl.: 16.

Introduction. Since the subject of the concept of systemogenesis is the system of professional activity of public servants, the interaction in it will occur between its elements, namely: processes, conditions, prerequisites for their occurrence, mechanisms, methods, resources and ways to ensure the professional activities of public servants; as well as between the structural elements themselves (subsystems, the individual constituent elements). To clarify the specifics, essence and development of the system of professional activity of public servants, it is advisable to analyze its properties, to reveal 
additional features of functioning, to identify weaknesses in order to develop methods and ways of effective development. In addition, a separate study of the phenomenon of robustness as one of the characteristics of a direct relationship to the object of our study has not been sufficiently studied. The research problems of this property are aimed at identifying the influence of such factors as: legal; functional; organizational; institutional; competency; motivational and others.

Literature Review. The work of many scientific researchers is devoted to the development of the professional activities of public servants and its various aspects, in particular Strokovich G. (2010). "Quality of functioning of the enterprise: internal and external aspects" [1], Alliluyko A. And Eremenko V. (2017) "Robust stability and quality functional evaluation of linear discrete systems with matrix uncertainties" [2], Lazorenko V. and Kharchenko V. (2017) "Robust method of determining the optimal level of training on the dispatcher simulator" [3], Yermolieva T., Ermolev Yu., Havlik P., Monier A., Lecler D., Kraxner F., Khabarov N. and Obersteiner M. (2015) "Systematic Analysis of Robust Strategic Solutions for the Planning of Secure Food, Energy, and Water Supply Based on the Stochastic GLOBIOM Model [4], Alekseenko T., Anishchenko V. and Ball. G. (2011). "White Paper of National Education of Ukraine" [14], Protasova N. (2000). "Theoretical foundations of training civil servants in the system of training and advanced training" [15] and others.

The concept of robustness was disclosed both in the system as a whole and in the use of specific robust methods for studying scientific problems in the fields of management, economics, and in a number of technical and mathematical approaches. In particular, in economics, the concept of robust design is used in the context of the design of ensuring the stability of products to external factors. Thus, an approach has been applied by which the quality and reliability of the products are correlated. This approach was proposed by James Mack Lynn as part of a list of aspects of product development in the context of quality-reliability. V. Strokovich considered robustness in enterprise quality management systems, including the relationship between the categories of quality, reliability and efficiency [1]. New methods for analyzing robust stability and optimizing discrete feedback control systems have also been developed, and a robust stabilization problem has been proposed and a quadratic quality criterion for linear discrete systems with matrix uncertainties is estimated. [2]. In addition, a robust method was used to determine the optimal level of training on a flight control simulator in aviation [3]. The development of adequate approaches to the system analysis of geospatial robust solutions for long-term coordinated management of interconnected land use systems is presented. A new stochastic Global Biosphere Management Model is considered, which allows us to analyze the safe supply of food, energy, water, taking into account the interdependence of countries and the possibility of global diversification of systemic risks [4].

Aims. The purpose of this work is to reveal the essence of the phenomenon of robustness to the system of professional activity of civil servants in the 
context of the formation of the concept of system genesis of the professional activity of civil servants. The object of this study is the professional activities of public servants. The subject of scientific research is the robustness of the system of professional activity of public servants.

To do this, the following tasks:a) to reveal the essence of robustness to the systemogenesis of the professional activities of public servants; b) to identify signs of robustness of the system of professional activity of civil servants and indicate the possibility of applying this property in the development of the concept of system genesis of the professional activity of civil servants.

Methods. A complex of general scientific and special research methods was used in the work, which made it possible to provide a comprehensive study of the problem and obtain reliable conclusions and results. The main research methods are complex, because from the standpoint of studying the systemogenetic approach of both scientific research, use both the methodology of scientific research and the methodology of practical activity. In the context of using the methodology of scientific research, a system of methods for scientific research of a systemogenetic approach in the theory of public administration has been formed, and in the context of using the methodology of practical activity, a system of methods for organizing and carrying out practical activities for the determination, consolidation and practical implementation of public administration has been formed.

Results. Since the subject of the concept of systemogenesis is the system of public administration, the interaction in it will occur between its elements, namely: processes, conditions, prerequisites for their occurrence, mechanisms, methods, resources and ways to ensure public administration; as well as between the structural elements themselves (subsystems, the individual constituent elements).

To clarify the specifics, essence and development of public administration, it is advisable to analyze its properties, to reveal additional features of functioning, to identify weaknesses for the development of methods and ways of effective development. The phenomenon of robustness as one of the characteristics in direct relation to the object of our study to date, has not been discovered and investigated. The research problems of this property are aimed at identifying the impact on the system of public administration of such factors as: legal factors; functional factors; organizational factors; institutional factors; competency factors; motivational factors and others.

The study for the first time reveals the essence of the effects of the phenomenon of robustness on public administration in the context of the formation of systemogenesis as a paradigm of public administration. A common problem in this context is the development of a scientific, methodological and organizational and legal framework with a view to the effective functioning of the system of public administration. Unresolved parts of this problem are the study of the characteristics of the system of public administration and determining the directions of the effective functioning of the system. In 
particular, the scientific development of the concept of robustness is required as one of the characteristics of the system of public administration.

The concept of robustness was disclosed both in general to systems and in the use of specific robust methods in the study of scientific problems in the fields of management, economics, and in a number of technical and mathematical approaches. So in economics, the concept of robust design is used in the context of design ensuring the stability of products to external factors. Thus, an approach is applied that correlates the quality and reliability of the products. This approach was proposed by James Mack Lynn as part of a list of aspects of product development in relation to the scientific approach of "qualityto-reality". Strokovich V. considered robustness in enterprise quality management systems, including the relationships of categorization, reliability and efficiency [1]. In addition, science has developed new methods for analyzing robust stability and optimizing discrete feedback control systems and proposing a solution to the robust stabilization problem and estimating the quadratic quality criterion for linear discrete systems with matrix uncertainties [2]. A robust method was used to determine the optimal level of training on a flight control simulator in aviation [3]. Scientists have presented the development of adequate approaches to the system analysis of geospatial robust solutions for long-term coordinated management of interconnected land use systems. A new stochastic Global Biosphere Management Model is also considered, which allows us to analyze the safe supply of food, energy, water, taking into account the interdependence of countries and the possibility of global diversification of systemic risks [4].

Robustness is usually understood as the ability of a system to maintain partial operability and / or efficiency when changing its individual elements or subsystems. Robustness as a characteristic is applied not only to system elements, but also to processes, techniques, and technologies. So, Schipanov V.V. defines robustness as a state in which the characteristics of technologies and processes are not sensitive to the effects of destabilizing factors [5]. In pharmacy, robustness has found its application in the development of analytical techniques. In particular, it is indicated that robustness is the ability of an analytical technique not to be exposed to small changes (specified) by the analyst under the conditions of the technique. In particular, researchers study the time stability of analytical solutions, extraction times, and the like. So it should be noted that the following effects on the results are usually identified: the difference in the experience of analysts; environmental conditions (temperature, humidity) reagents (various suppliers) [6].

The application of the concept of systemogenesis determines that the activity of a system, its components to achieve a goal, an action using certain means is nothing but the interaction of the functions of the system and its elements. The system of public administration is a complex system with inherent features for such systems, namely: a) the openness of the system; b) the ability to self-organize; c) hierichism and polystructuralism at the sub-levels of 
organization to the systemogenesis of object-systems; d) reproducibility of the system under the conditions of the launch of hierarchical systemogenesis.

To consider the issue of the volume of the system of public administration and the formation of the concept of systemogenesis, it becomes necessary to distinguish subsystems of public administration. The main of them, which we study as composite systems in our study: a) the legal system of public administration; b) the functional competence system of public administration; c) the institutional system of public administration; d) the psychological system of public administration.

Thus, the processes of systemogenesis are developing both in each individual subsystem-object, and as a whole in the system of public administration. Since robustness concerns the structural elements of the system of public administration, it seems appropriate to consider the following types of changes in the system: structural and non-structural. Non-structural changes in the system of public administration are characterized by issues of volume, content and quality of filling of the constituent elements of the system.

For example, the quality of the constituent elements (assessment of the professional activities of civil servants, the level of competence of civil servants, the amount of functional load on the job, etc.) through non-structural changes are most manifested in the functional competence, psychological and motivational aspects. Structural changes in the system of public administration usually occur in institutional and competence aspects. It should be noted that in general, government management activity is formed from the perspective of the functioning of institutional forms of both a state institution, position, and from the perspective of functional, organizational and competence aspects, therefore, scientists suggest considering them comprehensively [7].

So, in a broad sense, we believe that the robustness of the system of public administration is a property of the system to maintain effectiveness and a margin of stability when changing the parameters of its functioning.

Let us try to identify signs of robustness using the psychological system of civil servants as one of the components of public administration. The psychological component in public administration is formed from various components and is constantly in its development under the influence of external and internal factors of influence. We single out its main components such as: motivational, orientational, cognitive-operational.

At the same time, given the specifics of the functioning of the public administration system as a whole - its hierarchical nature, legally defined standards, procedures and requirements for the work of its elements - public servants, it is necessary to critically analyze developments in other areas of activity.

So, the motivational component in the interpretation of A. Glushko covers attitudes, interests and aspirations that closely correspond with pedagogical activity. It is based on a professional and pedagogical orientation, which is considered as a person's personal desire to apply his knowledge in the chosen 
managerial sphere. It expresses a positive attitude towards the profession, inclination, interest and desire to improve professionally. Also, the pedagogical orientation determines the stability, depth and breadth of professional interests and pedagogical ideals. In turn, the level of formation of professional interest affects the nature of self-improvement and the work of a future specialist on himself in the context of realizing his own professional and personal potential [8].

The orientation component includes value-professional guidelines based on professional ethics, professional and pedagogical ideals, attitudes, principles, beliefs and willingness to act in accordance with them. In the interpretation of A. Glushko, the main element of the orientational component determines the value orientations of the personality, the professional and pedagogical horizons and the level of its depth. Its basic elements include generalized professional knowledge, attitudes, beliefs, principles and willingness to act in practical situations in accordance with the indicated positions. Professional-pedagogical convictions are especially distinguished as an important substantive aspect of psychological readiness for professional activity [9].

This is due to the fact that they provide a sequence of professional actions, commitment of pedagogical work and communication. The content of readiness for professional pedagogical activity also includes professional education. At the same time, attention is focused on the fact that not only the latter determines the success of a specialist. An important role is given to professional ethics based on moral standards, assessment and self-esteem, control and self-control, respect for the norms and requirements of public life, as well as the ability to instill universal human standards in colleagues and students [10].

The cognitive-operational aspect of psychological readiness includes: attention, presentation, perception, memory, pedagogical thinking and abilities, knowledge, actions, operations and activities. These phenomena are considered as mandatory components and the key to successful professional activity. The specificity of the specialist's attention is emphasized and revealed, which consists in his ability to switch, distribute, move around objects, while remaining stable, concentrated and focused on actions.

Important among others are determined by such elements of the cognitiveoperational component of readiness as pedagogical thinking, which manifests itself in the ability to identify pedagogical situations, phenomena, facts, recognize, model them, and predict possible consequences; pedagogical abilities, covering pedagogical observation, pedagogical foresight and presentation. The next important element is professional skills related to knowledge of the body language, the correct use of verbal and non-verbal means [11].

It is also noted that the purposeful formation of professional attention, memory and representation is an important factor in increasing psychological readiness for work in "man-man" systems. Therefore, in terms of methodology, A. Glushko sets the task of organizing the training of future teachers in such a 
way as to best show the connection of educational material with the future profession. With the focus of knowledge and special skills on future professional activities, they become effective tools. In addition, the unity of theoretical and practical preparation and formation is ensured. the necessary level of professional readiness for activity.

Thus, the study of the manifestations of robustness on the formation and development of systemogenesis as a paradigm of public administration is advisable to distinguish into two blocks: a) the robustness of public administration; b) the robustness of self-organization of the system of public administration (system genesis aspect). The first version of the component of self-organization is professional competence. Considering the learning process in accordance with professional self-organization, we can talk about the inherent in each individual's own individual way of mastering knowledge, the method of appropriation of skills and the way of reproducing skills perceived in the learning process.

This is a self-organizing, individually directed amateur activity of the individual. Thus, in the process of postgraduate education, the manager masters and improves professional competencies, acquires a communicative culture and the like. However, the individual himself confronts the world as an independent individual world of "I", so self-organization acts as a condition, process and the result of his personal development [12].

The system of vocational training of civil servants is part of the system of professional activity of civil servants, as a whole component of the functional competence of the entire system of public administration.

The need for training, retraining and advanced training of a civil servant arises when "they need help to implement certain changes in work within the schedule and in accordance with the necessary standards of central and local executive authorities, local authorities" [13].

Indeed, before each level of the state-administrative hierarchy certain tasks are posed, on the basis of which the requirements for the professional and personal qualities of a public servant are formed. Therefore, the realization of the need for training, retraining and advanced training is associated with increasing the efficiency and competence of state managers by developing the ability to identify a problem, develop and make compromise decisions, reach a common agreement, and hold consultations and negotiations.

The specifics of the development process in the advanced training format is determined by the need to formulate programs and courses on the range of problems that a public servant should be able to solve; for certain periods allotted for obtaining knowledge and practical development of relevant skills. In addition to the above, psychological support of the development of the personality of a civil servant in the system of vocational education is important.

It manifests itself in a change in social reality due to the emergence of new social roles, new activities and group norms, as well as through the emergence of a large number of vague social situations, as a result of which a person often 
does not have specific requirements for the goals and results of his activities [14].

The effectiveness of the development process largely depends on its direction. At the same time, a change in the educational paradigm should be taken into account: from informative to developing [15].

An important sign of the robustness of the systemogenesis of public administration is the ability of the system to produce what it needs. This explains the concept of systemogenesis of complex systems, to which we include the public administration system as a whole[16]. That is, a system that can act both independently and externally is controlled, under certain conditions, is able to function independently and create appropriate products.

Conclusions. Based on the foregoing, we can draw the following conclusions: this is how we disclosed the concept of robustness in the context of the analysis of state management activities and applied it for the first time to government management activities as a system formation. It is defined in the broad sense that the robustness of the system of state management activity is the property of the system to maintain effectiveness and the stability margin when changing the parameters of its functioning. In particular, structural and nonstructural uncertainties are defined that determine the change in the quantity and quality of system elements. So systemogenesis is a process of self-organization in the narrow sense, therefore the robustness of systemogenesis is the ability of processes of self-organization of a system to maintain this property, effectiveness in case of failure of self-organization of its individual elements or subsystems. That is, in case of failure of the self-organization of one of the components of the system of public administration, the system retain the ability to self-organize and maintain efficiency.

The disclosure of robustness as one of the characteristics of the system of public administration has led to the conclusion that it is possible to apply this concept to the process of systemogenesis of public administration. In this paper, it is delimited and pointed to the differences between two characteristics of robustness: a) robustness of the system of public administration; b) robust systemogenesis of public administration.

It is proved that the robustness of the system of public administration indicates the property of the system of public administration with the loss / change / uncertainty of one of the elements of the system to continue to function. That is, the absence, change or uncertainty of one of the processes, prerequisites for their occurrence, mechanisms, methods, resources or ways to ensure public administration does not stop the functioning of the entire system of public administration and the public administration system as a whole. Manifestations of robustness primarily affect the system in the conditions of the appearance of a large number of uncertain social and political situations, reform of management systems, socio-political and professional reality. It has been revealed that in the context of a systematic analysis of the systemogenesis of state management activity, the basis of its self-organization may be such 
features: organization spontaneous generation, the emergence from a certain set of integral objects of the outlined level of a new holistic system with its own specific laws; processes through which the system maintains a certain level of organization when changing external and internal conditions of its functioning; type of processes associated with the improvement and self-development of such systems that are able to accumulate and use past experience.

\section{References:}

1. Strokovich, G.V.(2010). Quality of functioning of the enterprise: internal and external aspects. Kharkiv: NUA [in Ukrainian].

2. Alliluyko, A.M., Eremenko, V. O. (2017). Robust stability and quality functional evaluation of linear discrete systems with matrix uncertainties. TNTU,1, 126-137 [in Ukrainian].

3. Lazorenko, V., Kharchenko, V. Robust method of determining the optimal level of training on the dispatcher simulator. Retrieved from: http://jrnl.nau.edu.ua /index.php/visnik/article/view/12287 [in Ukrainian].

4. Yermolieva, T.Yu., Ermolev, Yu.M., Havlik, P., Monier, A., Lecler, D., Kraxner, F., Khabarov, N., \& Obersteiner, M. (2015). Systematic Analysis of Robust Strategic Solutions for the Planning of Secure Food, Energy, and Water Supply Based on the Stochastic GLOBIOM Model. Kybernetyka y systemnii analyz, 1, 144-154. Retrieved from: http://dspace.nbuv.gov.ua/handle /123456789/124766 [in Russian].

5. Shchipanov, V.V, Chernova, Y.K, Krylova, S.A. (2005). Mathematical modeling of educational processes. Toliatty: THU [in Russian].

6. Grizodub, A.I., Leont'ev, D.A., Dotsenko, T.N., Denysenko, N.V. (2003). Criteria for linear dependence parameters in the validation of analytical methods for HFCs. Aktualni pytannia farmatsevtychnoi ta medychnoi nauky i praktyky, 10, 30-32 [in Russian].

7. Carp, M.I. (2017). Status of Civil Servant: Functional, Organizational and Competent Aspects. Derzhavne budivnytstvo DRIDU NADU. Retrieved from: http://www.kbuapa.kharkov.ua/ebook/db/2017-1/doc/3/03.pdf [in Ukrainian].

8. Glushko, O.O. Development of students' psychological readiness for professional activity. Retrieved from: http://www.psyh.kiev.ua /Development_ of_students_psychological_prepared_to_professional_activities [in Ukrainian].

9. Akimov, O.O. (2016). Professional competencies of civil servants as a factor of modernization of higher education. Publichne uriaduvannia, № 1, 189-199 [in Ukrainian].

10.Akimov, O.O. (2019). Conceptual bases of systemogenesis of professional activity of civil servants in Ukraine. Kyiv: Tsentr uchbovoi literatury [in Ukrainian].

11.Akimov, O.O. (2020).Trends in the development of public service activity as a basis for the paradigm of the systemogenesis of state administrative activity. Investytsii: praktyka ta dosvid, 3, 135142. DOI: 10.32702 / 2306-6814.2020.3.135.[in Ukrainian].

12.Novachenko, T.V., Yasko, N.V . (2013). Self-organization of civil servant activity: national and European experience. Kyiv: NADU [in Ukrainian].

13.Monday, V.G., Khmelevskaya, O.M., Molchanova, Yu.O. (2005). Theoretical-methodological substantiation and methodology of studying the need for training of state-administrative personnel on the issues of European and Euro-Atlantic integration of Ukraine. Kyiv: NADU [in Ukrainian].

14.Alekseenko, T.F., Anishchenko, V.M., Ball, G.O. (2011). White Paper of National Education of Ukraine. Kyiv: Kyivsk. un-t im. Borysa Hrinchenka [in Ukrainian].

15.Protasova, N.G.(2000). Theoretical foundations of training civil servants in the system of training and advanced training. Kyiv: NADU [in Ukrainian].

16.Akimov, O., Karpa, M., Parkhomenko-Kutsevil, O., Kupriichuk, V., \& Omarov, A. (2020). Entrepreneurship education of the formation of the e-commerce managers professional qualities. Journal of Entrepreneurship Education, 23(S1). 